\title{
Extinction of active avoidance as a measure of passive avoidance in hippocampectomized rats ${ }^{1}$
}

\author{
DONALD V. COSCINA ${ }^{2}$ and LEONARD \\ LASH, ${ }^{3}$ Bucknell University, Lewisburg, \\ Pa. 1783 ?
}

Rats with large, aspiration lesions of the hippocampus, neocortical lesions, or normal controls were first trained to actively avoid (AA) shock in a one-way shockbox, and later to passively avoid $(P A)$ the previously safe compartment following one forced extinction trial. Both hippocampectomized and cortically lesioned $S$ s displayed deficits in $A A$. Although no statistical differences were found across groups during $P A$ testing, the possibility of a PA deficit was considered.

Rats suffering from bilateral hippocampal damage are known to be deficient in learning to inhibit an approach to either food (Isaacson \& Wickeigren, 1962 ) or water (Kimble, Kirkby, \& Stein, 1966) following shock. In the past, one explanation for such behavior has been to ascribe an enhanced perseverative tendency, i.e., an inability to withhold motor responses, to the hippocampectomized animal (Isaacson \& Wickelgren, 1962; Kimble et al, 1966). More recent work, however, indicates that these same animals may possess a heightened appetitive drive for food (Kimble \& Coover, 1966) and/or water (Kimble \& Coover, 1966; Pizzi \& Lorens, 1967). The possibility that such animals may be more hungry or thirsty than controls questions the nature of these earlier passive-avoidance deficits. In other words, do these animals fail to inhibit an appetitive approach following shock because of an avoidance deficit or because of an approach increment?

The present experiment was undertaken to examine passive-avoidance (PA) behavior that was not contingent upon Ss having learned a previous, appetitive approach response, hence circumventing the chance of $S s$ possessing differential appetitive drives during response-inhibition testing. For this purpose, a shock vs shock conflict was employed, in which a previously learned one-way active-avoidance (AA) response was to be suppressed following one shock trial in the previously safe goal side (i.e., forced extinction). In an earlier paper, we found that when rats with large hippocampal lesions were trained to a criterion on the AA task, then immediately tested for PA in such a paradigm under massed trials throughout, Ss were deficient on both the $\mathrm{AA}$ and PA measures (Coscina \& Lash, 1969). Because the type of practice may have an effect on hippocampectomized Ss' performance during such behavioral tests (Liss, 1968; Coscina \& Lash, 1969), we employed essentially the same paradigm as in our earlier study but trained Ss under distributed training trials. In this way, we hoped to ascertain the differences, if any, in performance on the two avoidance measures.

\section{METHOD}

The Ss used were 35 male hooded rats (Long-Evans strain) that were 120-140 days of age at the onset of the experiment. Before training, 10 rats sustained extensive damage of the hippocampus bilaterally, 12 received bilateral lesions of the neocortex overlying the hippocampus, and the remaining 13 served as unoperated controls. Prior to surgery, all Ss were handled for at least 5 days. Aspiration lesions (Lash, 1964) were induced during a one-stage operation under sodium pentobarbital anesthesia (Nembutal, $50 \mathrm{mg} / \mathrm{kg} \mathrm{IP}$ ). Following surgery, a 2-week recovery period was allowed all animals, during which time they were weighed and handled daily and maintained on oral sulfathiozole (in Ss' drinking water).

All training and testing took place in a one-way shockbox. The apparatus, which has been described elsewhere (Coscina \& Lash, 1969), was painted flat grey in both compartments. A transparent, plastic gravity door separated the two compartments until a doorbell buzzer (CS) was sounded, at which time it dropped completely out of the shockbox. The room in which all experimentation took place was equipped with a constant light source and a background of white noise (75-80 dB).

On the 1st day of training, each $S$ was allowed to explore both sides of the shockbox for $5 \mathrm{~min}$. After this acclimation period, $\mathbf{S}$ was placed on the start side. Ten seconds after his entry, the CS sounded and the gravity door dropped simultaneously. If $S$ remained in the starting area for longer than $5 \mathrm{sec}$, a shock of 0.25 to $0.50 \mathrm{~mA} \mathrm{dc}$ was delivered to his feet until a UR was made or until $60 \mathrm{sec}$ of CS-US pairing had elapsed. In either case, $S$ was then removed and confined during the intertrial interval (ITI) in a solitary, darkened chamber. The time from the initiation of the CS to $S$ 's crossing to the goal side was recorded via a printout counter as a measure of latency. Each rat received 10 distributed trials per day for 3 consecutive days.

On Day 4, the first four trials were conducted as before. On Trial 5, however, each $S$ was shocked in the hitherto safe area, the goal side, after a successful AA had been made. Since Ss would often return to the goal side at least once more during this forcedextinction trial, shock remained on for $60 \mathrm{sec}$.

No further shocks were given in either compartment on any subsequent trial. Ss were tested as before for 5 remaining trials on Day 4, plus 10 trials on the next 2 successive days, as during AA training but minus shock. If a rat did not enter the goal area within $60 \mathrm{sec}$, he was scored as completely passively avoiding and was removed until his next trial. The ITI for all trials during both $\mathrm{AA}$ and PA testing was 6-7 min. Throughout the experimental period, Ss were housed in individual cages and allowed food and water ad lib.

Upon completion of the study, Ss were sacrificed with a lethal dose of sodium pentobarbital, then perfused intracardially with $0.9 \%$ saline followed by $10.0 \%$ formalin. All brains were allowed to fix for 2 weeks, then were frozen and sectioned at 24 microns, and every 10 th section through the lesioned area retained for mounting and staining with thionin. RESULTS

The aspiration lesions in both the hippocampal and cortical groups were essentially the same in locus and size as those reported earlier (Coscina \& Lash, 1969). Complete lesion information is available upon request.

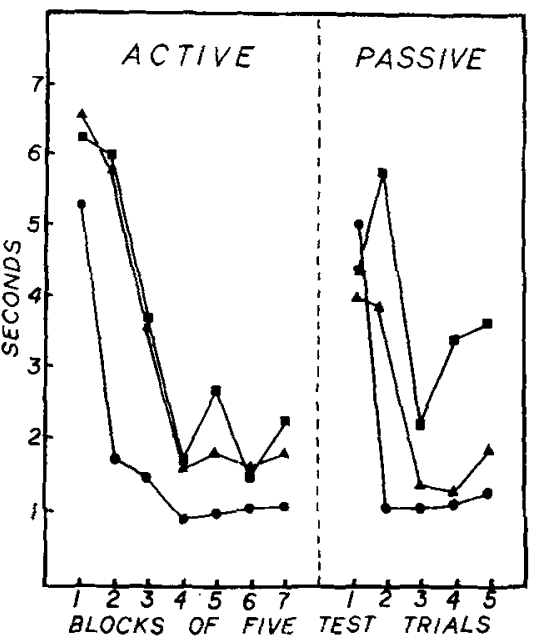

Fig. 1. Latencies, in seconds, for normal (circles), cortically-lesioned (squares), and hippocampectomized (triangles) rats, expressed as means of group medians for blocks of five active avoidance and passive avoidance trials. 
Figure 1 depicts the latency of entry into the goal side per group, as plotted from the means of group medians, for blocks of five trials during AA and PA testing. Considering the AA data first, it appears that the normal rats displayed a small, but reliable, increment in their performance, as compared to the two lesioned groups. Because of a lack of homogeneity of variance among groups, a Kruskal-Wallis analysis of variance was employed to determine the significance of the error differences among the three groups tested. An error was operationally defined as an escape from shock. An $\mathrm{H}$ of 11.1 was obtained $(\mathrm{df}=2)$ that was significant $(\mathrm{p}<.01)$. Two-tailed Mann-Whitney U-tests, undertaken on all possible pair combinations, revealed that normal Ss committed fewer errors $(p<.002)$ than did either of the two operated groups, but the latter two groups did not differ from each other.

An analysis of variance undertaken on the mean number of seconds to enter the goal side during PA testing revealed no significant differences across groups.

\section{DISCUSSION}

The finding that bilateral hippocampectomy is followed by impaired acquisition of a one-way $\mathrm{AA}$ is in accord with our earlier findings (Coscina \& Lash, 1969) as well as with reports by Olton \& Isaacson (1968). Of particular interest is that our cortically lesioned animals, like those of Olton \& Isaacson (1968), showed similar deficits in AA. Certain procedural artifacts may be responsible for this debility in the present study, since, in our previous paper, cortically-lesioned Ss performed as well on AA as did normals. In the experiment reported here, the shockbox was painted a flat grey throughout; also, the gravity door, which was transparent, slid completely out of the box upon release. In the previous study, the goal side was differentiated from the grey start side by painting the former flat black. Also, the gravity door, which was opaque, slid only partially out of the box when the CS was sounded, leaving a $2 \frac{1 / 4}{4}$ in. barrier that animals had to hurdle to make the appropriate response. Finally, the entire experiment was conducted within 1 day as opposed to the 6 days reported here; the ITI used earlier was also shorter (2-3 min). Aside from the differences in distribution of training trials, it is clear that, in the previous study, Ss had more visual cues as well as a more discrete response to make than those reported here. Thus, while hippocampectomy disnupted AA regardless of modifications in these parameters, neocortical damage affected learning only when ITIs were lengthened and the number of visual cues were decreased. This debility on the part of cortically-lesioned Ss may reflect a heightened threshold for Ss to utilize available sensory and/or motor cues associated with learning the AA response.

Our finding that hippocampectomized rats did not differ from the other groups tested on the PA measure is seemingly at odds with previous reports (Isaacson \& Wickelgren, 1962; Kimble et al, 1966). Since our Ss were not required to inhibit a previously learned appetitive approach, our data could be construed as supporting the notion that the more classic PA deficits reflect a heightened appetitive drive state for food or water rather than an inability to withhold responding. On the other hand, in our previous study (Coscina \& Lash, 1969), which employed sated Ss in a similar paradigm, hippocampectomized Ss were deficient on PA tests; this mediates against the "increased appetite" concept.

Considering the fact that our hippocampectomized rats were deficient in AA acquisition may provide an explanation for their apparently normal PA behavior. In our earlier paper, although hippocampally lesioned Ss required more trials than did controls to make the required 10 consecutive AAs, they did eventually perform to criterion. As reported here, similarly lesioned rats did not attain as high a level of AA proficiency. Hence, the lack of a PA deficit in our experimental group may reflect their poor AA performance, i.e., it was easier for them to extinguish in $\mathrm{AA}$ responding. If this explanation is correct, then hippocampectomized Ss were actually deficient in PA here, since, given their poorer AA behavior, they should have shown better PA than the controls, assuming similar gradients of extinction across groups. The tentative conclusion to be drawn, then, is that, regardless of modifications in distribution of practice, rats with large hippocampal lesions are deficient in one-way $A A$ acquisition and subsequent PA responding, at least when the latter is measured by extinction of the former.

\section{REFERENCES}

COSCINA, D. V., \& LASH, L. The effects of differential hippocampal lesions on a shock versus shock conflict. Physiology \& Behavior, 1969, 4, 227-233.

ISAACSON, R. L., \& WICKELGREN, W. O. Hippocampal ablation and passive avoidance. Science, 1962, 138, 1104-1106.

KIMBLE, D. P., \& COOVER, G. D. Effects of hippocampal lesions on food and water consumption. Psychonomic Science, 1966, 4, 91-92.

KIMBLE, D. P., KIRKBY, R. J., \& STEIN, D. G. A response perseveration interpretation of passive avoidance deficits in hippocampectomized rats. Journal of Comparative \& Physiological Psychology, $1966,61,141.143$.

LASH, L. Response discriminability and the hippocampus. Journal of Comparative \& Physiological Psychology, 1964, 57, 251-256.

LISS, P. K. Avoidance and freezing behavior following damage to the hippocampus or fornix. Journal of Comparative \& Physiological Psychology, 1968, 66, 193-197.

OLTON, D. S., \& ISAACSON, R. L. Hippocampal lesions and active avoidance. Physiology \& Behavior, 1968, 3, 719-724.

PIZZI, W, J., \& LORENS, S. A. Effects of lesions in the amygdalo-hippocampo-septal system on food and water intake in the rat. Psychonomic Science, 1967, 7, 187-188.

$$
\text { NOTES }
$$

1. This research was supported by Public Health Service Grant MH-12271 to the second author. The results of this experiment were reported at the 1967 meeting of the Eastern Psychological Association in Boston, Massachusetts.

2. Reprint requests should be sent to Donald V. Coscina, Department of Psychology, University of Chicago, 5848 South University Avenue, Chicago, 1ll. 60637 .

3. Present address: National Institute for Mental Health, Behavioral Sciences, Neuropsychology Section, 5454 Wisconsin Avenue, Chevy Chase, Md. 20203. 